\title{
МОДЕЛЮВАННЯ СКЛАДУ ЗБИРАЛЬНО-ТРАНСПОРТНОГО КОМПЛЕКСУ ДЛЯ ВРОЖАЮ ЗЕРНОВИХ ЯК СИСТЕМИ МАСОВОГО ОБСЛУГОВУВАННЯ
}

\section{В. Г. Загорянський, Т. В. Гайкова, В. Л. Хорольський, І. О. Кузєв}

Кременчуцький національний університет імені Михайла Остроградського

вул. Першотравнева, 20, м. Кременчук, 39600, Україна. E-mail: zagor_vlad@ukr.net

Запропоновано оптимізаційну модель визначення необхідної кількості автомобілів у складі збиральноготранспортного комплексу при збиранні врожаю зернових. В якості технологічної схеми прийнятий спосіб прямого комбайнування, як ресурсозберігаючий і прийнятий у більшості зернових господарств Полтавської області. Завдання полягає в знаходженні в складі збирального-транспортного комплексу такого співвідношення кількості комбайнів і автомобілів, що їх обслуговують, при якому в одиницю часу сума витрат, викликаних простоями комбайнів і витрат на утримання автомобілів (цільова функція запропонованої моделі) буде мінімальною. Розрахунки за відомими методиками не дозволяють визначити, чи будуть, при даному співвідношенні кількості комбайнів і автомобілів, комбайни наповнювати бункери зерном, а автомобілі своєчасно транспортувати зерно на тік або склади господарства. Для визначення змінних величин, які входять до виразу для цільової функції, середньої кількості наповнених бункерів зернозбиральних комбайнів (заявок на обслуговування) в одиницю часу і середнього часу очікування кожної заявки, розроблені проміжні та остаточні залежності з застосуванням теорії масового обслуговування. Для визначення оптимальної кількості автомобілів доцільно також розрахувати сумарні витрати, отримані як за прийнятої кількості автомобілів, так і при збільшеній їх кількості.

Ключові слова: модель, оптимізація, витрати, збирання, зернові, комбайнування, теорія масового обслуговування.

\section{МОДЕЛИРОВАНИЕ СОСТАВА УБОРОЧНО-ТРАНСПОРТНОГО КОМПЛЕКСА ДЛЯ УРОЖАЯ ЗЕРНОВЫХ КАК СИСТЕМЫ МАССОВОГО ОБСЛУЖИВАНИЯ}

\section{В. Г. Загорянский, Т. В. Гайкова, В. Л. Хорольский, И. О. Кузев}

Кременчугский национальный университет имени Михаила Остроградского

ул. Первомайская, 20, г. Кременчуг, 39600, Украина. E-mail: zagor_vlad@ukr.net

Предложена оптимизационная модель определения необходимого количества автомобилей в составе уборочно-транспортного комплекса при уборке урожая зерновых. В качестве технологической схемы принят способ прямого комбайнирования, как ресурсосберегающий и принятый в большинстве зерновых хозяйств Полтавской области. Задача состоит в нахождении в составе уборочно-транспортного комплекса такого соотношения количества комбайнов и обслуживающих их автомобилей, при котором в единицу времени сумма издержек, вызванных простоями комбайнов и расходов на содержание автомобилей (целевая функция предложенной модели) будет минимальной. Расчеты по известным методикам не позволяют определить, будут ли, при данном соотношении количества комбайнов и автомобилей, комбайны наполнять бункера зерном, а автомобили своевременно транспортировать зерно на ток или склады хозяйства. Для определения переменных величин, входящих в выражение для целевой функции, среднего количества наполненных бункеров зерноуборочных комбайнов (заявок на обслуживание) в единицу времени и среднего времени ожидания каждой заявки, разработаны промежуточные и окончательные зависимости с применением теории массового обслуживания. Для определения оптимального количества автомобилей целесообразно также рассчитать суммарные расходы, полученные как для принятого количества автомобилей, так и при увеличенном их количестве.

Ключевые слова: модель, оптимизация, издержки, уборка, зерновые, комбайнирование, теория массового обслуживания.

АКТУАЛЬНІСТЬ РОБОТИ. Автомобільний транспорт $є$ основним видом транспорту в сільському господарстві, на частку якого припадає до $80 \%$ всього обсягу перевезень. Транспортні витрати займають в загальному обсязі витрат на виробництво сільськогосподарської продукції значне місце - в собівартості сільськогосподарської продукції складають $15 \ldots 40 \%$ [1].

Відомо, що комбайнові способи збирання зернових $€$ домінуючими в сільськогосподарському виробництві [2]. Розрізняють два способи комбайнового збирання: пряме і роздільне комбайнування.

Пряме комбайнування здійснюють зернозбиральним комбайном, обладнаним фронтальним хедером (частиною комбайна, що представляє собою платформу 3 робочими частинами: ріжучим апаратом, мотовилом, транспортером і похилим елеватором). В процесі роботи агрегат скошує хлібну масу, обмолочує іiі та виділяє зерно. При цьому зерно над- ходить в бункер-накопичувач, а незернова частина врожаю в залежності від прийнятої технології - в копичник, укладається або подрібнюється і розкидається по полю.

Пряме комбайнування ефективно при збиранні рівномірно дозрілих посівів, полів з підсівом трав.

У більшості країн переважним визнається пряме комбайнування [2].

При визначенні потрібної кількості автомобілів для обслуговування зернозбиральних комбайнів у складі збирально-транспортного комплексу для відповідних природно-кліматичних умов за відомими методиками [3, 4] невідомо, чи буде при даному співвідношенні комбайнів і автомобілів досягнута ефективна робота збирально-транспортного комплексу, тобто чи комбайни будуть наповнювати бункери зерном, а автомобілі своєчасно транспортувати зерно на тік або склади господарства. 
Для перевезення сільськогосподарських вантажів, в тому числі врожаю зернових, найбільш часто використовують [1]:

- бортові автомобілі УАЗ-3303-01 (колісна формула - 4×4) вантажопідйомністю 800 кг, ГАЗ-53-12 $(4 \times 2)-4500$ кг, ЗИЛ-431410 і ЗИЛ-431510 $(4 \times 2)$ вантажопідйомністю 6000 кг, КамАЗ-5320 (6×4) вантажопідйомністю 8000 кг,

- автомобілі-самоскиди Урал-5557 (6×6) загальною вантажопідйомністю разом 3 причепом 23000 кг, КамА3-55102 (6×4) вантажопідйомністю 7000 кг, ГАЗ-САЗ-3507 і ГАЗ-САЗ-4509 (4×2) вантажопідйомністю 4250 кг, ГАЗ-САЗ-3502 и ГАЗ-САЗ-3508 3 попереднім підйомом кузова і вантажопідйомністю 3200 и 3700 кг відповідно, ЗИЛ-ММЗ-554М (4×2) вантажопідйомністю 5500 кг.

Незважаючи на велику різноманітність типів і марок зазначених автомобілів, залишається проблема створення більш універсального типорозмірного ряду автомобілів для перевезення сільськогосподарських вантажів в складних дорожніх умовах.

Під час руху по полю зернозбиральних комбайнів у складі збирально-транспортного комплексу постійно виникають заявки на обслуговування (розвантаження бункерів наповнених зерном в кузов автомобіля). Після задоволення заявки на обслуговування (розвантаження бункера) комбайн продовжує роботу і виникають нові заявки. Таким чином, роботу збирально-транспортного комплексу можна представити в якості замкнутої системи масового обслуговування [5], в якій в одиницю часу виникає $\lambda$ заявок на обслуговування ( $\lambda$ - інтенсивність вхідного потоку вимог (середня кількість вимог, що надходять в одиницю часу)) і кожен автомобіль (канал обслуговування) здатний задовольнити $\mu$ заявок в одиницю часу ( $\mu$ - інтенсивність каналу обслуговування (середня кількість обслужених вимог в одиницю часу).

Питомі витрати коштів (за годину простою) для комбайна в 3...4 рази вищі, ніж у автомобіля. Відмітимо, що збільшувати автомобілів кількість для виключення або зменшення простою комбайнів в очікуванні автомобілів, можливо лише до відповідної межі.

Потрібно знайти таке співвідношення кількості комбайнів і автомобілів, при якому сумарні витрати $\mathrm{C}$ (в одиницю часу (годину)) - сума витрат $\mathrm{C}_{\mathrm{K}}$, викликаних простоями комбайнів, $\mathrm{i}$ витрат $\mathrm{C}_{\mathrm{a}}$ на утримання автомобілів будуть найменшими, тобто має місце лінійна цільова функція:

$$
C=C_{\kappa}+C_{a}=c_{\kappa} \cdot \lambda \cdot W_{q}+c_{a} \cdot n_{a} \rightarrow \min ,
$$

де $\mathrm{c}_{\mathrm{\kappa}}-$ збиток від простою комбайна в очікуванні обслуговування, грн./год.; $\lambda$ - середня кількість наповнених бункерів (заявок на обслуговування) в годину; $\mathrm{W}_{\mathrm{q}}$ - середній час очікування кожної заявки, годин; $\mathrm{c}_{\mathrm{a}}$ - витрати на утримання автомобіля (амортизаційні відрахування, заробітна плата водієві, вартість паливно-мастильних матеріалів), грн/год.; $\mathrm{n}_{\mathrm{a}}-$ кількість автомобілів в збирально-транспортному комплексі.
Метою роботи є розробка оптимізаційної моделі для визначення раціональної кількості автомобілів в збирально-транспортному комплексі для збирання зернових із застосуванням методів теорії масового обслуговування.

МАТЕРІАЛ І РЕЗУЛЬТАТИ ДОСЛІДЖЕНЬ. Рівень обслуговування в системі є функцією інтенсивності обслуговування $\mu$ і кількості с паралельно працюючих сервісів [6-10]. Зазвичай розглядаються дві моделі прийняття рішень для визначення «відповідних» рівнів обслуговування для систем масового обслуговування: модель 3 вартісними характеристиками і модель бажаного рівня обслуговування. В обох моделях більш високий рівень обслуговування відповідає зменшенню часу очікування в системі. У цих моделях для пошуку рівноваги між конфліктуючими факторами (рівнем обслуговування і часом очікування в системі) використовуються функціональні показники обслуговуючої системи.

В моделі з вартісними характеристиками врівноважуються два конфліктуючих вартісних показника - витрати на обслуговування та втрати, зумовлені затримками в наданні послуг (час очікування клієнта). Ці види витрат конфліктують між собою, так як збільшення одного з них автоматично веде до зменшення іншого і навпаки.

Нехай рівень обслуговування являє змінна х, що дорівнює $\mu$ або с. Тоді модель 3 вартісними характеристиками можна представити в наступному вигляді [6]:

$$
c \boldsymbol{B}_{3}=c \boldsymbol{B}_{\text {oб }}+c \boldsymbol{b}_{\mathrm{o \psi}},
$$

де $\mathrm{cB}_{3}$ - середня загальна вартість в одиницю часу; св $_{\text {об }}$ - середня вартість обслуговування в одиницю часу; св $_{\text {оч }}$ - середня вартість очікування в одиницю часу.

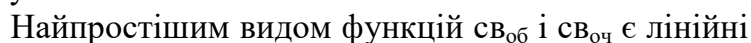
функції:

$$
\begin{gathered}
c b_{o \sigma}(x)=c_{1} x, \\
c 8_{o y}(x)=c_{2} L_{s},
\end{gathered}
$$

де $c_{1}$ - питома вартість на одиницю х в одиницю часу, $c_{2}-$ вартість очікування в одиницю часу на клієнта, що очікує; $\mathrm{L}_{\mathrm{s}}$ - середня кількість клієнтів, що знаходяться в системі.

Відомо [1], що при груповій роботі в складі збирально-транспортних ланок або комплексів загальна продуктивність всіх збиральних агрегатів (в нашому випадку, зернозбиральних комбайнів) повинна відповідати продуктивності групи транспортних засобів (автомобілів), що їх обслуговують, з умови їх спільної потокової роботи:

$$
W_{\kappa} \cdot n_{\kappa}=W_{a} \cdot n_{a},
$$

де $\mathrm{n}_{\kappa}, \mathrm{n}_{\mathrm{a}}$ - відповідно кількість зернозбиральних комбайнів і обслуговуючих їх автомобілів; $\mathrm{W}_{\mathrm{\kappa}}, \mathrm{W}_{\mathrm{a}}$ відповідно їх продуктивності, т/год.

Звідси необхідна кількість автомобілів:

$$
n_{a}=\frac{W_{\kappa} \cdot n_{\kappa}}{W_{a}} .
$$


За останньою залежністю неможливо визначити середню кількість комбайнів, що простоюють в черзі для розвантаження бункерів, і середню тривалість часу очікування автомобілів. Тому витрати від простоїв комбайнів при такому співвідношенні їх з автомобілями в збирально-транспортному комплексі за залежністю (6) оцінити неможливо.

Продуктивність транспортних і збиральних машин залежить від великої кількості факторів, вплив кожного з яких по-різному, причому дії деяких з них можуть взаємно врівноважуватися. Сумарний же ефект їх впливу призводить до того, що замість результату, який однозначно визначається, отримують різні результати.

На продуктивність зернозбирального комбайна впливає врожайність культури, що збирається, вологість зерна та соломи, зупинки за технологічними i технічними причинами і т. д. Продуктивність автомобілів на збиранні залежить від їх технічного стану, кваліфікації водія, середньої швидкості руху, дорожніх умов та інших чинників. Тому досягти повної узгодженості роботи комбайнів і автомобілів, щоб не було простоїв комбайнів в очікуванні транспорту і навпаки, практично неможливо.

Різноманіття факторів, що впливають на хід збирально-транспортних операцій, визначає імовірнісний характер процесу, що, в свою чергу, зумовлює технологічні простої автомобілів в очікуванні розвантаження. Якщо технологічно необхідна величина простоїв автомобілів в очікуванні навантаження не враховується при визначенні потреби в рухомому складі при комплектуванні збирально-транспортних бригад, будуть простоювати комбайни, в результаті чого їх вироблення знизиться на $10-15 \%$.

Найчастіше ж трапляються випадки, коли в збирально-транспортні бригади включається невиправдано велика кількість автомобілів, міркуючи приблизно так: чим більше автомобілів на поле, тим менше простої комбайнів. Ці міркування вірні до певних меж, тобто до тих пір, поки простої автомобілів в очікуванні навантаження не перевищать технологічно необхідну величину. Після цього простої комбайнів практично не знижуються, а простої автомобілів різко збільшуються. Часто в таких умовах спостерігається картина, коли кілька автомобілів чекають наповнення бункера одного і того ж комбайна.

Представляє великий практичний інтерес визначення технологічно необхідного значення тривалості простою автомобіля в очікуванні завантаження бункера зерна.

Для визначення цього параметра збиральнотранспортного процесу доцільно використовувати математичний апарат теорії масового обслуговування.

У математичної моделі збирально-транспортна бригада представляється у вигляді системи масового обслуговування 3 очікуванням, в якій обслуговуючим апаратом є автомобілі, а тим, що обслуговують, - комбайни.

Особливість роботи системи полягає в тому, що вимога, яка надійшла в систему (зупинка комбайна 3 повним бункером), заставши всі автомобілі зайнятими, змушена чекати своєї черги до тих пір, поки не звільниться один з автомобілів.
Після обслуговування (розвантаження бункерів) комбайни через деякий час знову стають джерелами вимог, тобто потік вимог надходить 3 обмеженого джерела, так що кількість вимог в системі не може перевищувати кількість комбайнів в бригаді (замкнута система).

В якості критеріїв, що характеризують ефективність функціонування системи, приймаються коефіцієнти простою комбайнів

$$
Q_{\kappa}=\frac{M_{1}}{M}
$$

і автомобілів

$$
Q_{a}=\frac{n_{1}}{n}
$$

де $\mathrm{M}_{1}$ - середня довжина черги комбайна в очікуванні обслуговування; М - кількість комбайнів в бригаді; $\mathrm{n}_{1}$ - середня кількість незайнятих автомобілів, що знаходяться на полі; $\mathrm{n}$ - загальна кількість автомобілів, що знаходяться на полі та готових до обслуговування комбайнів.

Готовим до обслуговування автомобіль вважається з моменту в'їзду на поле до моменту закінчення завантаження останнього бункера зерна, що перевозиться за рейс.

Під простоєм автомобіля розуміється загальний час перебування його на полі за винятком часу під'їзду до комбайнів, які подали сигнал готовності, часу розвантаження комбайнів, часу переїзду від останнього обслугованого комбайна до краю поля, під простоєм комбайна - час після наповнення бункера i подачі сигналу готовності за винятком часу під'їзду автомобіля і часу розвантаження.

У теорії масового обслуговування, як правило, розглядають найпростіший потік вимог, що надходять в систему в одиницю часу, який підпорядковується пуасонівському закону розподілу [11].

Для нашого випадку інтенсивність потоку заявок:

$$
\lambda=\frac{1}{-},
$$

де $t_{\sigma}$ - середнє значення інтервалу між надходженням чергових вимог (середній час наповнення бункера комбайна зерном), годин.

Пропускна здатність каналу обслуговування:

$$
\mu=\frac{1}{\bar{t}_{\text {об }}} n_{3},
$$

де $\bar{t}_{\text {об }}-$ середній час обслуговування однієї заявки, годин (в нашому випадку буде дорівнювати тривалості $\mathrm{t}_{\text {об }}$ обороту транспортного засобу); $\mathrm{n}_{3}-$ кількість заявок.

Тривалість обороту транспортного засобу, годин [12]:

$$
t_{\text {об }}=t_{n}+t_{3}+t_{2}+t_{\partial}+t_{B}+t_{x},
$$

де $\mathrm{t}_{\text {п }}-$ час руху автомобіля по полю, годин; $\mathrm{t}_{3}-$ час завантаження, годин; $\mathrm{t}_{\mathrm{r}}$ - час руху 3 вантажем, годин; $\mathrm{t}_{\text {д }}$ час оформлення документів, годин; $\mathrm{t}_{\mathrm{B}}-$ час вивантаження зерна з бункера комбайна, годин; $t_{x}-$ час руху без вантажу, годин. 
Відома також залежність (11) в іншій формі [13]:

$$
t_{\text {об }}=\frac{L_{c}}{\varphi \cdot V_{T}}+t_{n p},
$$

де $\mathrm{L}_{\Gamma}$ - шлях заповнення або спорожнення технологічної ємності, км; $\varphi$ - коефіцієнт використання часу пробігу:

$$
\varphi=\frac{L_{2}}{L_{2}+L_{x}},
$$

де $\mathrm{L}_{\text {г }}$ - шлях, що проходить транспортний засіб без вантажу, км; $\mathrm{V}_{\mathrm{T}}$ - середня технічна швидкість транспортного засобу, км/год.; $\mathrm{t}_{\text {пр }}$ - час простою транспортного засобу під завантаженням і розвантаженням, годин.

Приведена інтенсивність потоку заявок (інтенсивність навантаження каналу) $\rho$ виражає середню кількість заявок, що надходить за середній час обслуговування однієї заявки:

$$
\rho=\frac{\lambda}{\mu} .
$$

У сільськогосподарському виробництві найбільшого поширення набули системи масового обслуговування $з$ очікуванням [11], в яких заявка, що надійшла в момент часу (всі канали обслуговування зайняті), стає в чергу і чекає, поки не звільниться будь-який канал. Зернозбиральний комбайн 3 наповненим бункером не покидає систему і очікує чергового автомобіля для вивантаження зерна, тобто система з необмеженим очікуванням.

Для системи з очікуванням імовірність того, що система вільна, в системі відсутні заявки на обслуговування, тобто всі канали обслуговування (автомобілі) простоюють, жоден комбайн не готовий до вивантаження зерна [14]:

$$
P_{0}=\left(\sum_{k=0}^{n} \frac{\rho^{k}}{k !}+\frac{\rho^{n+1}}{n !(n-\rho)}\right)^{-1},
$$

де $\mathrm{n}$ - кількість усіх каналів обслуговування в системі (кількість автомобілів в збирально-транспортному комплексі).

Імовірність того, що в системі заходиться $\mathrm{k}(\mathrm{k}=$ $1, \ldots$, n) заявок:

$$
P_{k}=\frac{\rho^{k}}{k !} P_{0} .
$$

Підставивши значення з формули (14) в формулу (16), знайдемо

$$
\rho=\lambda \cdot \bar{t}_{\text {об }} .
$$

Для одноканальної системи коефіцієнт завантаження $\rho$ відповідає часу, при якому система зайнята обслуговуванням заявок. Різниця $1-\rho$ відповідає часу простоювання системи.

Для багатоканальної системи параметр $\rho$ дорівнює середньої кількості каналів, постійно зайнятих обслуговуванням, а різниця $P_{c e p}^{a}=n_{a}-\rho-$ середньої кількості каналів, що простоюють.

Величина $\rho$ не може бути довільною. Сталий режим існує тільки при $\rho<\mathrm{n}_{\mathrm{a}}$, а при $\rho \geq \mathrm{n}_{\mathrm{a}}$ система не впорається 3 обслуговуванням і черга буде рости необмежено.
Імовірність простоїв автомобілів в очікуванні розвантаження бункерів комбайнами:

$$
P_{o \psi}^{a}=\frac{P_{c e p}^{a}}{n_{a}}=\frac{n_{a}-\rho}{n_{a}},
$$

де $P_{c e p}^{a}-$ середня кількість каналів, що простоюють (автомобілів, що обслуговують), шт.; $\mathrm{n}_{\mathrm{a}}$ - кількість автомобілів в збирально-транспортному комплексі.

Середня довжина черги (кількість заявок, які очікують обслуговування):

$$
L_{q}=\frac{\rho^{n+1} \cdot P_{0}}{n ! n \cdot\left(1-\frac{\rho}{n}\right)^{2}} .
$$

Імовірність черги комбайнів:

$$
P_{o \psi}^{\kappa}=1-\sum_{k=0}^{n} P_{k}
$$

де $\sum_{k=0}^{n} P_{k}$ - сума ймовірностей того, що не зайнятий жоден канал (в системі немає заявок на обслуговування).

Середній час знаходження заявки в черзі (очікування кожної заявки):

$$
W_{q}=\frac{L_{q}}{\lambda} .
$$

Для розрахунку за запропонованою моделлю потрібно знати наступні параметри:

- характеристика умов збирання зернових (збиральна площа $\mathrm{F}$, га; врожайність пшениці $\mathrm{g}_{3}, \mathrm{~T} /$ га; відношення маси соломи до маси зерна $\delta$; густина зерна $\gamma$, т/м ${ }^{3}$; календарний термін збирання Д, днів; тривалість робочого дня $\mathrm{T}_{\text {рд }}$, годин; коефіцієнт використання часу зміни $\tau$; коефіцієнт метеоумов $\mathrm{K}_{\mathrm{M}}$; радіус перевезення зерна $\mathrm{R}$, км);

- характеристика зернозбирального комбайну (ширина захвату жатки $\mathrm{B}_{\mathrm{p}}$, м; пропускна здатність молотарки $\mathrm{g}_{\kappa}$, кг/с; ємність бункера $\mathrm{Q}_{\delta}, \mathrm{M}^{3}$; час вивантаження бункера $\mathrm{t}_{\mathrm{B}}$, хвилин; коефіцієнт технічної готовності $\mathrm{K}_{\mathrm{r}}$ );

- характеристика транспортного засобу (марка автомобіля; вантажопідйомність q, т; коефіцієнт використання вантажопідйомності $\alpha_{q}$; швидкість pуху Vp (з вантажем і без вантажу), км/год.; коефіцієнт технічної готовності $\mathrm{K}_{\text {г }}$ ).

Вихідними даними моделі, окрім постійних величин $\mathrm{c}_{\mathrm{\kappa}} \mathrm{i} \mathrm{c}_{\mathrm{a}}$, які входять до виразу для цільової функції, виступають:

- розрахункова кількість комбайнів $\mathrm{n}_{\mathrm{\kappa}} \mathrm{i}$ автомобілів $\mathrm{n}_{\mathrm{a}}$ в збирально-транспортному комплексі;

- тривалість завантаження $\mathrm{t}_{3} \mathrm{i}$ вивантаження $\mathrm{t}_{\mathrm{B}}$ бункеру комбайна, хвилин;

- тривалість обороту транспортного засобу (автомобіля) $\mathrm{t}_{\text {об̆ }}$, хвилин.

Якщо тривалості $\mathrm{t}_{3} \mathrm{i}_{\mathrm{в}}$ задані в хвилинах, то кількість бункерів комбайнів, які будуть заповнені за одну годину [12]:

$$
n_{\sigma}=\frac{60 n_{\kappa}}{t_{3}+t_{B}}
$$


На обслуговування буде надходити $\mathrm{n}_{б}$ бункерів на годину, тобто $\mathrm{n}_{\sigma}=\lambda$.

У кузов автомобіля поміщається один бункер зерна і за один рейс буде задовольнятися одна заявка на обслуговування, а пропускна здатність одного

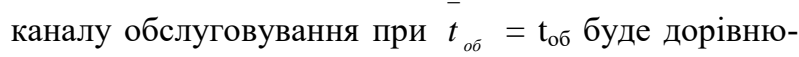
вати

$$
\mu=\frac{1}{t_{\text {об }}} .
$$

Зі збільшенням кількості автомобілів сумарні витрати від простоїв комбайнів і автомобілів спочатку знижуються, а потім зростають [12]. Тобто, для визначення оптимального значення цільової функції, доцільно розрухувати сумарні витрати, отримані як і за прийнятої кількості автомобілів, так і при збільшеній їх кількості. Кількість автомобілів, для якої сумарні витрати будуть мінімальними, буде оптимальною для розглянутого збирально-транспортного комплексу.

ВИСНОВКИ. Таким чином, розроблено оптимізаційну моделі для визначення раціональної кількості автомобілів в збирально-транспортному комплексі для збирання зернових із застосуванням методів теорії масового обслуговування.

Для цього розроблені проміжні та остаточні залежності для визначення змінних величин, які входять до виразу для цільової функції, - середньої кількості наповнених бункерів зернозбиральних комбайнів (заявок на обслуговування) в годину і середнього часу очікування кожної заявки, годин.

\section{ЛІТЕРАТУРА}

1. Зангиев А. А., Шпилько А. В., Левшин А. Г. Эксплуатация машинно-тракторного парка. Москва: КолосС, 2008. 320 с.

2. Машиностроение. Энциклопедия. Том IV-16. Сельскохозяйственные машины и оборудование / И. П. Ксеневич и др. Москва: Машиностроение, 2002. $720 \mathrm{c.}$

3. Валуев Н. В., Рудик В. М. Рациональная загрузка мобильных средств обслуживания комбайнов в уборочных комплексах. Механизация и электрификациия сельского хозяйства. 1994. № 11. С. 56-57.

4. Разработка методики выбора условий взаимодействия зерноуборочного и транспортного компле- ксов / Д. А. Музылев и др. Восточноевропейский журнал передовых технологий. 2016. № 2/3 (80). C. $11-21$.

5. Системологія на транспорті. Кн. IV. Основи теорії систем i управління / Е.В.Гаврилов, М. Ф. Дмитриченко, В. К. Доля та ін. Київ: Знання України, 2005. 344 с.

6. Таха Хемди. Введение в исследование операций. Москва: Издательский дом «Вильямс», 2005. 912 c.

7. Shramenko N. Y., Shramenko V. O. Mathematical model of the logistics chain for the delivery of bulk cargo by rail transport. Науковий вісник національного гірничого університету. 2018. № 5. С. 136-141.

8. Загорянський В. Г., Гайкова Т. В., Хорольский В. Л., Кузєв І. О. Зниження втрат картоплі в післязбиральний період шляхом покращення умов транспортування і супутніх операцій. Вісник Кременчуцьького національного університету імені Михайла Остроградського. 2018. Вип. 4 (111). С. 81-86.

9. Moroz M. M., Korol S. O., Boiko Y. O. Social traffic monitoring in the city of Kremenchuk. Актуальні проблеми економіки: науковий економічний журнал. 2016. № 1 (175). С. 385-398.

10. Iryna Trunina, Volodymyr Zahorianskyi, Olena Zahorianska, Dmytro Moloshtan. Ensuring Competitiveness of Logistics Service by Selecting the Type of Storing Single-Piece Cargoes. International Journal of Engeneering and Technology. Vol 7, No 4.3 (2018). Special Issue 3. P. 537-544.

11. Самойленко Н. И., Скоков Б. Г. Исследование операций (Математическое программирование. Теория массового обслуживания). Харьков: ХНАГХ, 2005. $176 \mathrm{c}$.

12. Артемов М. Е. Курсовое и дипломное проектирование по эксплуатации машинно-тракторного парка. Красноярск: Краснояр. гос. аграр. ун-т, 2008. $326 \mathrm{c}$.

13. Механизация и электрификация сельскохозяйственого производства / А. П. Тарасенко и др. Москва: КолосС, 2004. 552 с.

14. Афанасьев М. Ю., Суворов Б. П. Исследование операций в экономике: модели, задачи, решения. Москва: ИНФРА-М, 2003. 444 с.

\section{MODELING OF HARVESTING TRANSPORT COMPLEX COMPLETION FOR THE CROPS HARVEST AS A QUEUEING SYSTEM}

\section{Zagoryanskii, T. Haykova, V. Khorol'skii, I. Kuzev}

Kremenchuk Mykhailo Ostrohradskyi National University

vul. Pershotravneva, 20, Kremenchuk, 39600, Ukraine. E-mail: zagor_vlad@ukr.net

Purpose. The article aims to develop an optimization model for determining the required number of vehicles for transporting grain crops using queueing theory service in order to increase the efficiency of this transportation by road transport. Methodology. The methodological basis of the study is a systematic approach to the study of issues of development and improving the efficiency of transport process in agricultural production. The study was carried out by economic and mathematical modeling of the composition of the harvest-transport complex. The methods of queueing theory were used as methods in the process of identifying the essence of phenomena that cover the complex of the studied issues. Results. It has been established that the study of the "grain combines - vehicle" system on the example of grain farms of Poltava region using the methods of queueing theory is relevant. Road transportation of grain in Ukraine is in demand in the agricultural regions of the country, including Poltava region, for the delivery of the harvested grain from fields to elevators and other storage sites. In agricultural production, the most labor-intensive and difficult in terms of 
organization, material, monetary and labor costs is the process of harvesting crops, including the grain harvest. To optimize the parameters of this transport process, it is possible to develop a process model using queuing theory and performing calculations on it. The number of vehicles at which the total costs caused by combines downtime and vehicles maintaining cost will be minimal, is considered to be optimal for the considered harvest-transport complex. Originality. An optimization mathematical model for the process of transport service of combine harvesters, taking into account the conditions of this process, has been developed. The criterion for the effectiveness of the choice (the objective function of the mathematical model) is the sum of the costs caused by combines downtime and vehicles maintaining cost (the objective function of the proposed model) provided they are minimized. The factors that determine these costs are highlighted and the calculated dependencies for their determination are developed. The complex method of optimizing the technology of harvesting and transporting grain from farms that grow crops, with the participation of road transport, was further developed. Practical value. The developed model for determining the optimal number of vehicles as part of the harvest and transport complex for exporting grain crops using the methods of queueing theory can be used by companies supplying motor transport services and farms that grow grain crops to increase the volume and increase the efficiency of road transport for grain crops. It seems promising to develop an algorithm for this model and a program for optimizing the number of cars in the harvest-transport complex for harvesting grain.

Key words: model, optimization, costs, harvesting, grain, combining, queueing theory.

\section{REFERENCES}

1. Zangiev, A. A., Shpilko, A. V., Levshin, A. G. (2008), Ekspluatatsiya mashinno-traktornogo parka [Machine and tractor fleet operation], KolosS, Moscow, Russia.

2. Ksenevich, I. P. (2002), Mashinostroyeniye. Entsiklopediya. Tom IV-16. Sel'skokhozyaystvennyye mashiny $i$ oborudovaniye [Engineering. Encyclopedia. Volume IV-16. Agricultural machinery and equipment], Mashinostroenie, Moscow, Russia.

3. Valuev, N. V., Rudik, V. M. (1984), "Ratsional'naya zagruzka mobil'nykh sredstv obsluzhivaniya kombaynov v uborochnykh kompleksakh" [Efficient loading of mobile maintenance facilities of combines in harvesting complexes], Mekhanizatsiya i elektrifikatsiya sel'skogo khozyaystva, Vol. № 11, pp. 56-57.

4. Muzyev, D. A. (2016), "Razrabotka metodiki vybora usloviy vzaimodeystviya zernouborochnogo i transportnogo kompleksov" [Development of methods for selecting the conditions of interaction between the crops and transport complexes], Vostochnoyevropeyskiy zhurnal peredovykh tekhnologiy, Vol. № 2/3 (80), pp. 11-21.

5. Havrylov, E. V., Dmytrychenko, M. F., Dolya, V. K. (2004), Systemolohiya na transporti. Knyha IV. Osnovy teoriyi system i upravlinnya [Systemology in transport. Book IV. Fundamentals of the theory of systems and management], Znannja Ukrajny, Kiev, Ukraine.

6. Takha, Khemdi (2005), Vvedeniye $v$ issledovaniye operatsiy [Introduction to operations research], Izdatelskiy dom «Vil'yams», Moskva, Russia.

7. Shramenko, N. Y., Shramenko, V. O. (2018), Mathematical model of the logistics chain for the delivery of bulk cargo by rail transport, Naukovyy visnyk natsiona'noho hirnychoho universytetu, Vol. 5, pp. 136-141.
8. Zahoryanskyy, V. G. (2018), “Znyzhennya vtrat kartopli V pislyazbyral'nyy period shlyakhom pokrashchennya umov transportuvannya i suputnikh operatsiy" [Reduction of potato losses in the postharvest period by improving transportation conditions and accompanying operations], Transactions of Kremenchuk Mykhailo Ostrohradskyi National University, Iss. 4 (111), pp. 81-86.

9. Moroz, M. M., Korol, S. O., Boiko, Y. O. (2016), Social traffic monitoring in the city of Kremenchuk, Aktual'ni problemy ekonomiky: naukovyy ekonomichnyy zhurnal, Vol № 1 (175), pp. 385-398.

10. Trunina, I., Zahorianskyi, V., Zahorianska, O., Moloshtan, D. (2018), Ensuring Competitiveness of Logistics Service by Selecting the Type of Storing Single-Piece Cargoes, International Journal of Engeneering and Technology. Vol 7, No 4.3, Special Issue 3, p. 537-544.

11. Samoylenko, N. I., Skokov, B. G. (2005), Issledovaniye operatsiy (Matematicheskoye programmmirovaniye. Teoriya massovogo obsluzhivaniya) [Operations Research (Mathematical programming. Theory of mass service)], KhNAGKh, Kharkov, Ukraine.

12. Artemov, M. Ye. (2008), Kursovoye i diplomnoye proyektirovaniye po ekspluatatsii mashinnotraktornogo parka [Course and diploma design for the operation of the machine and tractor fleet], Krasnoyar. gos. agrar. un-t, Krasnoyarsk, Russia.

13. Tarasenko, A. P. (2004), Mekhanizatsiya $i$ elektrifikatsiya sel'skokhozyaystvenogo proizvodstva [Mechanization and electrification of agricultural production], KolosS, Moscow, Russia.

14. Afanasyev, M. Yu., Suvorov, B. P. (2003), Issledovaniye operatsiy $v$ ekonomike: modeli, zadachi, resheniya [Operations Research in Economics: models, tasks, solutions], INFRA-M, Moscow, Russia. 